\title{
Arsenic speciation by hydride generation-Quartz furnace atomic absorption spectrometry. Optimization of analytical parameters and application to environmental samples
}

\author{
N. Molénat ${ }^{1}$, A. Astruc ${ }^{1}$, M. Holeman ${ }^{1}$, G. Maury ${ }^{2}$, R. Pinel ${ }^{1 *}$ \\ ${ }^{1}$ Laboratoire de Chimie Analytique Bioinorganique et Environnement, E.P.132, Département de Chimie, \\ Faculté des Sciences et Techniques, Avenue de l'Université, 64000 Pau, France \\ ${ }^{2}$ Département de Chimie Organique Fine, Université Montpellier II des Sciences et Techniques, \\ 34095 Montpellier 5, France
}

\begin{abstract}
Analytical parameters of hydride generation, trapping, gas chromatography and atomic absorption spectrometry detection in a quartz cell furnace (HG/GC/QFAAS) device have been optimized in order to develop an efficient and sensitive method for arsenic compounds speciation. Good performances were obtained with absolute detection limits in the range of $0.1-0.5 \mathrm{ng}$ for arsenite, arsenate, monomethylarsonic acid (MMAA), dimethylarsinic acid (DMAA) and trimethylarsine oxide (TMAO). A $\mathrm{pH}$ selective reduction for inorganic arsenic speciation was successfully reported. Application to the accurate determination of arsenic compounds in different environmental samples was performed.
\end{abstract}

Keywords. Atomic absorption spectrometry - hydride generation - arsenic - arsenite - arsenate - methylarsenic acid dimethylarsenic acid - trimethylarsine oxide - speciation - environmental samples.

\section{Introduction}

Arsenic is an ubiquitous and potentially toxic element in the environment. Present in soils [1,2] and in waters [3], both naturally and as the result of human activities - agriculture, industry or coal burning plants for example [4,5] - it undergoes many physical, chemical and biological changes in the different ecosystems [6-8]. Biological reactions occurring in terrestrial $[9,10]$ and marine organisms [11-14] convert inorganic arsenate (AsV) and arsenite (AsIII) to monomethylarsonic acid (MMAA), dimethylarsinic acid (DMAA) and trimethylarsine oxyde (TMAO). Moreover, microorganisms are able to reduce arsenate in arsenite previously released into solution prior to methylation $[15,16]$.

In order to understand these biochemical processes and since arsenic toxicity depends on its speciation [17], several techniques have been developed to determine the concentrations of the different arsenic compounds [18-22]. Methods based on HPLC separation are more and more often used in arsenic speciation and a review of the main techniques using this separation has been recently published by Guerin et al. [23]. AAS [24,25], AFS [26], ICP-AES [27,28] or ICP-MS [29-31] seem to be the most sensitive detection methods hyphenated to the HPLC separation, specially if an hydride generation is performed before detection. Therefore on line combinations such as HPLC/HG/AAS [30,32-34],
HPLC/HG/ICP-MS [35] or HPLC/HG/AFS [36-38] are now well described. However, chromatographic dilution reduces sensitivity that may be then not sufficient for the analysis of environmental samples. Moreover, the development of these methods requires important investing and high running costs limiting their use in most laboratories. Reported by several authors, the hyphenated HG/GC/AAS method with cryogenic trapping offers an excellent sensitivity owing to the separation of matrix and analytes during hydride generation, the preconcentration by trapping in liquid nitrogen associated to the selectivity and sensitivity of AAS detection. It is simple to operate with a fully automated system suitable for routine analyse and requires little investing. It has already widely used for the study of biochemical processes or the determination of AsIII, AsV, MMAA and DMAA in environmental samples [39,41-52].

Since the first system presented by Andreae in 1977 [39], some modifications have improved the performances of the HG/GC/AAS method [49-52]. However, few papers deal with the effects of analytical parameters in the development of such a method.

The aim of this paper was to systematically examine each of adjustable parameters in the whole experimental process using standard solutions in order to improve the cryogenic trap HG/QFAAS procedure before using it to the determi- 
nation of AsIII, AsV, MMAA and DMAA in environmental samples.

\section{Materials and methods}

\section{Apparatus}

An automatic device for HG/QFAAS has been previously developed in our laboratory for organotin speciation [53]. A schematic representation of this apparatus is shown on figure 1 .

The system is constituted by an hydride generation flask made of pyrex, a magnetic stirrer, a glass U-tube (length: $705 \mathrm{~mm}$; id, $4 \mathrm{~mm}$ ) packed with $10 \%$ OV 101 on chromosorb 80/100 mesh which can be immersed in liquid nitrogen and a quartz tube atomizer (length: $14 \mathrm{~cm}$; i.d: $12 \mathrm{~mm}$ ) heated by a commercial ceramic furnace (Perkin Elmer). Absorbance signals are treated by a SpectrAA-10 atomic absorption spectrometer (Varian) and a Shimadzu CR4AChromatopac integrator, a $\mathrm{PC} 16 \mathrm{~N}$ I/O card driving the process. Tygon tubing assume connections between the reaction vessel, the trap and the quartz cell. These connections are as short as possible in order to minimize adsorption phenomena.

\section{Standards and reagents}

The $1000 \mathrm{mg}$ As.L ${ }^{-1}$ standards solutions of AsIII $\left(\mathrm{As}_{2} \mathrm{O}_{3}\right.$ "pro analysis", MERCK), $\mathrm{AsV}\left(\mathrm{H}_{3} \mathrm{AsO}_{4}\right.$, Spectrosol), monomethylarsonic acid di-sodium salt (MMAA, CARLO ERBA, purity > $98 \%$ ), cacodylic acid sodium salt trihydrate (DMAA, CARLO ERBA, purum) were prepared in suprapure water (Millipore system, Milli Q - MilliRo). A stock solution of $\mathrm{As}_{2} \mathrm{O}_{3}$ in $\mathrm{NaOH} 0.2 \%$ was used for the preparation of arsenite (AsIII) standard. These stock solutions, stored at $4{ }^{\circ} \mathrm{C}$ in the dark in polyethylene bottles, were stable for at least 6 months [21]. They were diluted daily to

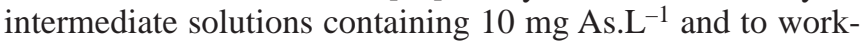
ing solutions containing $100 \mu \mathrm{g}$ As.L ${ }^{-1}$. A $1000 \mathrm{mg} \mathrm{As.L^{-1 }}$ TMA standard solution was prepared by solubilisation of commercial TMA (STREM, purity $99 \%$ ) in methanol. The working solution was also prepared in this solvent.

A $6 \% \mathrm{NaBH}_{4}$ (FLUKA, purity $99 \%$ ) solution was prepared daily in suprapure water and stabilised with $\mathrm{NaOH} 0.1$ M (MERCK, suprapur).

Oxalic acid (quality RPE) was purchased from CARLO ERBA. Phosphate buffer $0.05 \mathrm{M}$ was prepared with appropriate amounts of $\mathrm{KH}_{2} \mathrm{PO}_{4}$ and $\mathrm{K}_{2} \mathrm{HPO}_{4}$ from MERCK ("pro analysis").

\section{Operating procedure}

Aliquot of samples (0.05 to $50 \mathrm{ml}$ depending on the As concentration level) were introduced into the hydride generation reactor with an appropriate buffer. The reactor containing a final volume of $50 \mathrm{ml}$ was connected to the device. A run

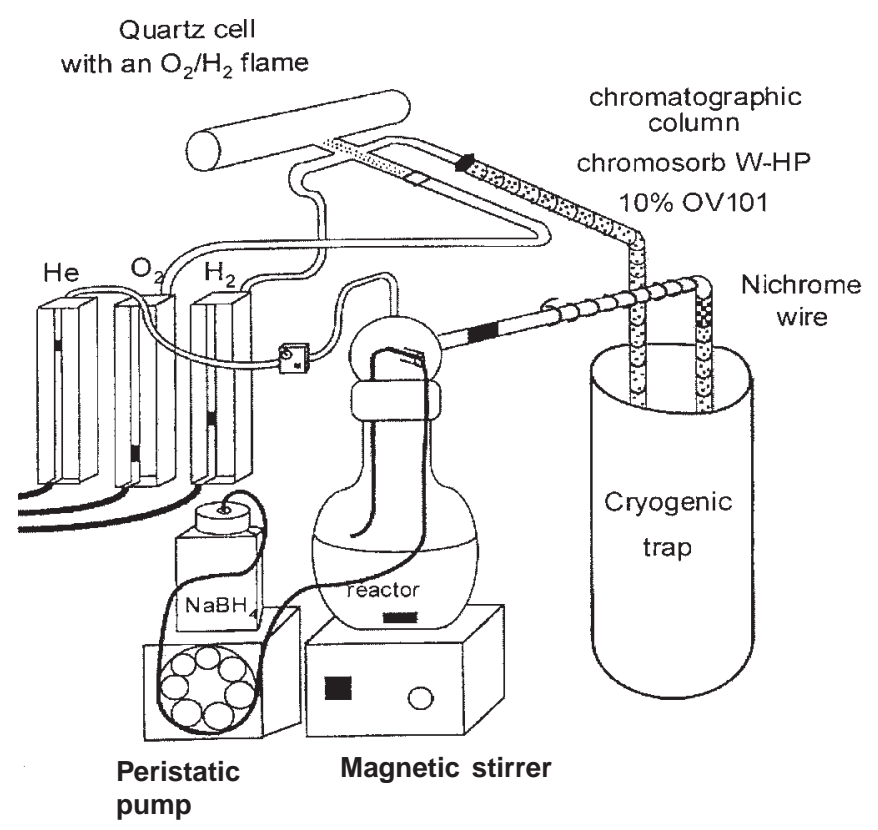

Fig. 1. Schematic representation of the automated HG/QFAAS apparatus.

was initiated by the starting of helium flushing and the system is purged during $30 \mathrm{~s}$ before the glass packed column was immersed into liquid nitrogen. The $\mathrm{NaBH}_{4}$ solution was then progressively added using a peristaltic pump under continuous stirring. Under these conditions, arsenic compounds are reduced to the corresponding arsines. They are swept out of the solution by the continuous helium flux and trapped into the refrigerated column. The cold trap was then removed and warmed up at room temperature. Arsines formed were sequentially volatilized according to their boiling points. The column was further heated with a nichrome wire to remove water condensed in the trap. Arsines were pushed on to the electrically heated quartz cell where they were atomised. Sensitivity was improved by the adjonction of an $\mathrm{H}_{2} / \mathrm{O}_{2}$ flame in the furnace. The analytical experiment was totally automated, and signal treatment was performed by a Shimadzu integrator.

In order to determine the five As species (AsIII, AsV, MMAA, DMAA, TMAO), two different experiments were required: at low $\mathrm{pH}$, AsIII and $\mathrm{AsV}$ were both reduced to $\mathrm{AsH}_{3}$ and organoarsenic derivatized to their corresponding alkylarsines. A second analysis at higher $\mathrm{pH}$ was necessary to determine specifically AsIII. AsV was then quantified by difference between total inorganic As (experiment I) and AsIII (experiment II).

\section{Results and discussion}

The quality of an analytical procedure depends on its selectivity, quantitativity, sensitivity, reproducibility and analysis 
time. We have examined and optimized these factors for the hydride generation step from AsIII, AsV, MMAA and DMAA, the trapping of corresponding arsines and the detection phase. Due to its restricting use, TMA standard was not considered in the optimization.

\section{Optimization of hydride generation}

It has been previously reported that arsenic compounds are reduced by $\mathrm{NaBH}_{4}$ to corresponding arsines only when they are under acidic form [54]. pKa values are 9.29, 2.24, 4.19, 1.78 ( $1^{\text {st }}$ acidity) for $\mathrm{H}_{3} \mathrm{AsO}_{3}$ (AsIII), $\mathrm{H}_{3} \mathrm{AsO}_{4}$ (AsV), $\mathrm{CH}_{3} \mathrm{AsO}(\mathrm{OH})_{2}$ (MMAA) and $\left(\mathrm{CH}_{3}\right)_{2} \mathrm{AsO}(\mathrm{OH})$ (DMAA) respectively. Adjustement of the $\mathrm{pH}$ in the hydride generator allows a selective reduction of these acids. This procedure is commonly used to obtain the speciation of inorganic arsenic since both AsIII and $\mathrm{AsV}$ are reduced to the same arsine $\mathrm{AsH}_{3}[18,39,40,43,44,46,47,52]$.

An optimal $\mathrm{pH}$ range of 1-2 has been proposed in the literature to perform the simultaneous quantification of total inorganic arsenic (AsIII + AsV), MMAA and DMAA using $\mathrm{HCl}[43,44,46], \mathrm{H}_{2} \mathrm{SO}_{4}[40,47]$ or oxalic acid [40] (Exp. I). The determination of As III alone has been reported at $\mathrm{pH} 4[52], 5[43,44,47], 6[39,46]$ or 7 [46] leading to different conclusions about successful $\mathrm{pH}$ conditions (Exp. II).

\section{Experiment I: As(III+V), MMAA, DMAA determination}

\section{Nature of the acid}

Hydrochloric, sulfuric, nitric and oxalic acid solutions of $\mathrm{pH}$ ranging between 1 and 2 were tested. As already indicated by Braman et al. [40], sulfuric acid induced undesirable arsine molecular rearrangements (the reduction of DMAA led to the detection of peaks corresponding to the monomethylarsine $\mathrm{CH}_{3} \mathrm{AsH}_{2}$ and inorganic $\mathrm{AsH}_{3}$ compounds). Moreover, we have observed inorganic arsenic contamination (1 to $1.5 \mathrm{ng}$ ) in commercial acids of high purity $\left(\mathrm{HCl}, \mathrm{HNO}_{3}\right)$. Despite the As blank level $(0.5 \mathrm{ng})$, oxalic acid was proved to be the best to maintain $\mathrm{pH}$ solutions between 1 and 2 .

\section{Effect of reagent concentration}

Three concentrations of oxalic acid were tested: $0.5 \%$ $(\mathrm{pH} 1.7), 1 \%(\mathrm{pH} 1.5)$ and $2 \%(\mathrm{pH} 1.2)$. The amount of $\mathrm{NaBH}_{4}$ necessary to obtain a maximal hydride generation rate for each of the four arsenic compounds studied was determined. Signals increased with the amount of added $\mathrm{NaBH}_{4}$ until a maximal and constant value was reached which depends on the acid buffer capacity. Buffer capacity has to be sufficient to maintain the $\mathrm{pH}$ in the hydride generator at a value close to the $\mathrm{pH}$ required for each arsenical optimal reduction. The observed relationships between the final $\mathrm{pH}$ of the reaction medium and the formation of each arsine is shown in figure 2.

An acid concentration of $0.5 \%$ has a low buffer capacity and the pH increases quickly to 9 when alkaline $\mathrm{NaBH}_{4}$ solution is added. Acidity was then no more sufficient for
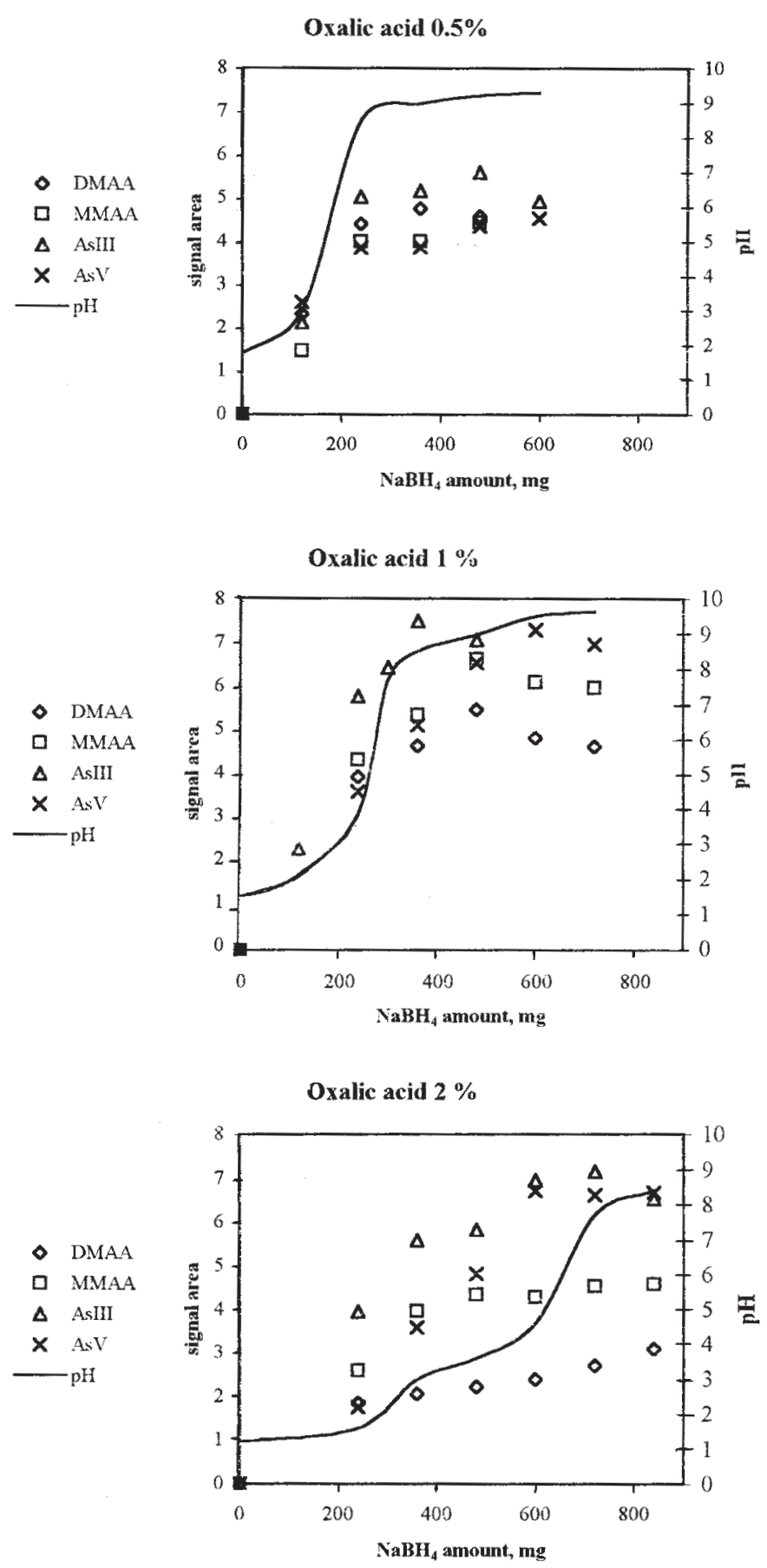

Fig. 2. Evolution of final $\mathrm{pH}$ and signal areas with the addition of $\mathrm{NaBH}_{4}$ in oxalic acid $0.5 \%, 1 \%$ or $2 \%$.

hydridation reaction leading rapidly to a constant and low signal intensity for each arsine. Under these $\mathrm{pH}$ conditions, arsines from AsIII and DMAA showed the same signal evolution but AsV gave a lower signal than AsIII.

When $1 \%$ oxalic acid was used, the reaction mixture remained acidic for a longer time, thus allowing an 


\section{Original articles}

improved arsine and methylarsine production. $\mathrm{AsH}_{3}$ yields increased with the $\mathrm{pH}$ and became stable when the $\mathrm{pH}$ was close to 9. AsIII or AsV signals had about the same sensitivity, although AsIII was apparently reduced faster than $\mathrm{AsV}$ probably due to a preliminary AsV reduction prior to $\mathrm{AsH}_{3}$ formation. Monomethylarsine or dimethylarsine signals tended to become independent of $\mathrm{pH}$ : the hydridation reaction was maybe limited when $\mathrm{pH}$ value was high enough to ionize these acids.

A $2 \%$ oxalic acid concentration led to a maximal hydridation of each arsenic compound before neutralization by $\mathrm{NaBH}_{4}$ was reached. However, the dimethylarsine production yield in such acidic condition was lower than for the other arsenicals.

Thus, optimal yields of arsines were obtained when a sufficient amount of $\mathrm{NaBH}_{4}$ was added and with an acid concentration sufficient to maintain longer acidic conditions. Below $1 \%$, AsIII and AsV had different hydridation yields thus prevented the evaluation of $\mathrm{AsV}$ concentration by a simple substraction procedure. Yields of $\mathrm{AsH}_{3}$ were stable when the acid concentration was above $1 \%$. On the contrary in high acidic conditions dimethylarsine formation decreased. Finally, maximal yields of monomethylarsine were not influenced by initial acid concentration. The effect of initial acidity on signals is illustrated in figure 3.

In conclusion, an oxalic acid concentration of $1 \%$ represents finally a good compromise for the optimisation of all arsenic species signals. The $\mathrm{NaBH}_{4}$ amount added in the reactor was fixed at $600 \mathrm{mg}$.

\section{Experiment II: AsIII determination}

\section{Nature of buffer}

Three buffer solutions were tested: citrate buffer $(\mathrm{pH} \mathrm{5),}$ acetate buffer $(\mathrm{pH} \mathrm{5)}$ and phosphate buffer ( $\mathrm{pH}$ 6.8). With citrate or acetate buffers partial hydridation of AsV was observed confirming previously published results [46]. In a $0.05 \mathrm{M}$ phosphate buffer ( $\mathrm{pH}$ 6.8) and below an amount of $200 \mathrm{ng}$ of AsV introduced in the reactor, we didn't observe any noticeable hydridation of AsV (figure 4). These results are similar to those obtained by Masscheleyn et al. using a Tris $\mathrm{HCl}$ buffer ( $\mathrm{pH} 6$ and $\mathrm{pH}$ 7) or an acetate buffer (pH 5) [46]. Phosphate buffer was retained for next determinations.

The quality of As III determination depends on the specificity of this experiment.

So to analyse an environmental sample, the initial quantification of total inorganic As (exp. I) was necessary so that less than $200 \mathrm{ng}$ of total inorganic arsenic is introduced in the reactor. The ratio AsIII/AsV in the aliquot of solution analysed has to be above $0.1 \%$ [0.2 ng (LD of AsIII) $\div 200 \mathrm{ng}$ (LD of AsV)]. Thus, in presence of high AsV concentrations, dilutions are necessary to accurately determine AsIII without noticeable AsV interference.

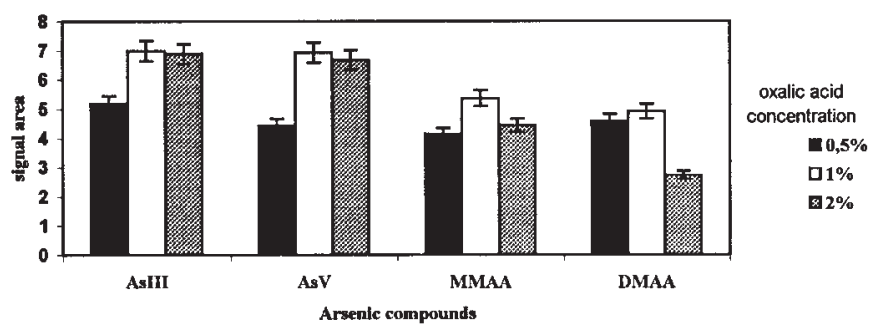

Fig. 3. Effect of initial oxalic acid concentration on signal areas.

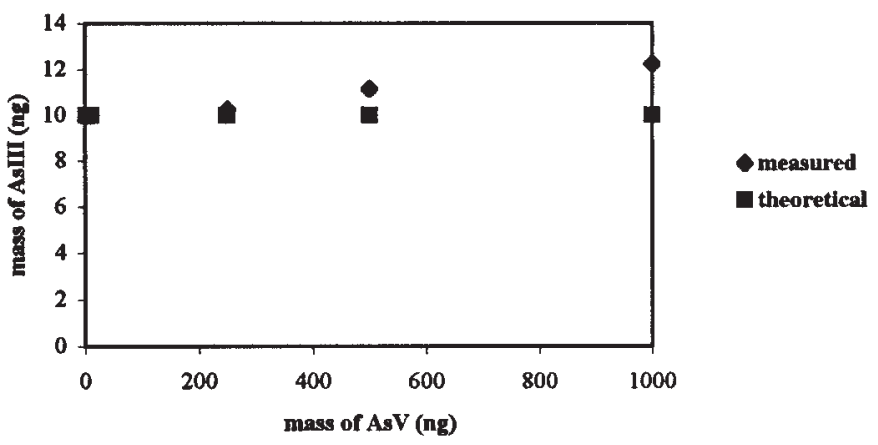

Fig. 4. Effect of AsV on the determination of a $10 \mathrm{ng}$ AsIII amount in a phosphate buffer.

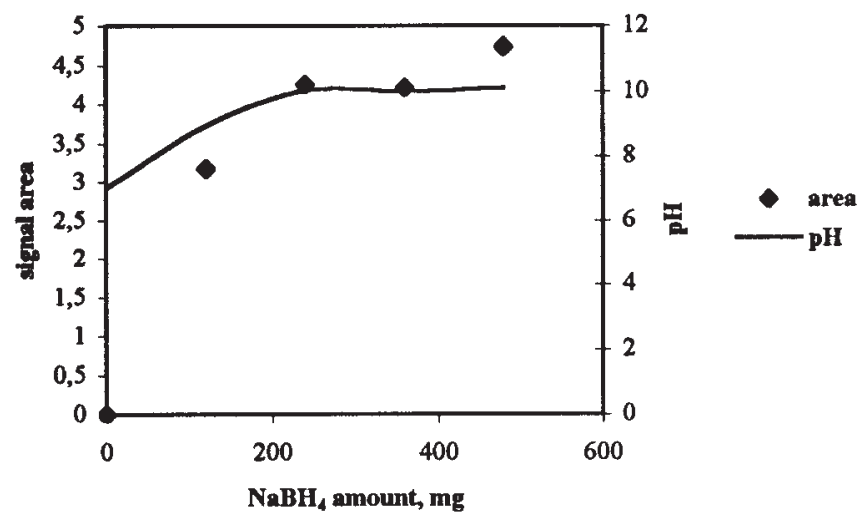

Fig. 5. Evolution of final $\mathrm{pH}$ and signal area of a $10 \mathrm{ng}$ As III amount with the addition of $\mathrm{NaBH}_{4}$ in phosphate buffer.

\section{Amount of $\mathrm{NaBH}_{4}$}

As in the experiment $\mathrm{I}$, a $6 \% \mathrm{NaBH}_{4}$ solution was used and the rate of addition was fixed to $2 \mathrm{~mL} \cdot \mathrm{min}^{-1}$. Initial $\mathrm{pH}$ being 6.8, we observed that the addition of $240 \mathrm{mg}$ of the reducing agent was sufficient to increase $\mathrm{pH}$ to 9 and to obtain a maximal AsIII peak area (Fig. 5). Consequently, $\mathrm{NaBH}_{4}$ addition time was reduced, thus decreasing the total analysis duration from 13 to $10 \mathrm{~min}$. 


\section{Original articles}

\section{Optimization of trapping conditions}

\section{Column packing}

The column consists of a glass U-tube of $705 \mathrm{~mm}$ total length. A $180 \mathrm{~mm}$ length only is immersed in liquid nitrogen. With empty glass columns, no peak were observed. The tube was then packed with $10 \%$ OV 101 on chromosorb GAW/DMCS (80/100 mesh), a chromatographic stationnary phase already used for organotin compounds determination [44]. This packing allowed a good chromatographic separation of arsines for more than a thousand experiments. It may be damaged if the helium flow rate used is too high, leading to overpressures in the system. Moreover, the column heating step necessary to eliminate water condensed during the cold trapping period has to be brief to prevent from column volume variations. Without a strict control of these parameters, preferential pathways appeared in the column packing and induced peak splitting phenomena.

\section{Carrier gas flow rate}

The carrier gas flow rate influences generally both the sensitivity and the selectivity of the analysis. Increasing the flow rate of the carrier gas affects trapping efficiency of the arsines and resting time of arsenic atoms in the atomiser cell. Its effect has been scarcely reported in the literature [43]. Using the conditions of experiment I, we observed a decrease of peak areas when increasing the initial carrier gas flow rate. The most volatile arsine, $\mathrm{AsH}_{3}$, was the most affected by a high helium flow rate with a maximal area in the range of 0 to $150 \mathrm{ml} \cdot \mathrm{min}^{-1}$ decreasing to $80 \%$ at $550 \mathrm{ml} \times \mathrm{min}^{-1}$ flow rate. Similarly, monomethylarsine and dimethylarsine peak areas both decreased to $90 \%$ of their maximum values (Fig. 6).

In experiment $\mathrm{I}\left(\mathrm{pH}\right.$ 1.5), $\mathrm{AsH}_{3}, \mathrm{CH}_{3} \mathrm{AsH}_{2}$ and $\left(\mathrm{CH}_{3}\right)_{2} \mathrm{AsH}$ could be detected without helium flushing since $\mathrm{H}_{2}$ produced during the reduction process was sufficient to be used as carrier gas. However, signal intensities were low. Initial helium flow rate was then adjusted to $100 \mathrm{ml} \times \mathrm{min}^{-1}$.

In experiment II $(\mathrm{pH} 6.8)$, a $100 \mathrm{ml} \times \mathrm{min}^{-1}$ helium flow rate was found to be insufficient to carry arsines quantitatively to the detector because of lower $\mathrm{H}_{2}$ production at this $\mathrm{pH}$. The remaining arsines may interfer on the next analysis leading to memory effects and bad reproducibility. The helium flow rate was then fixed to an initially value of $600 \mathrm{ml} \times \mathrm{min}^{-1}$ which decreased during the experiment to $200 \mathrm{ml} \times \mathrm{min}^{-1}$ owing to column evolution at liquid $\mathrm{N}_{2}$ temperature. In these conditions, excellent peak resolution, optimal sensitivity and good reproducibility without damage to the column packing were obtained. Moreover water vapor was efficiently swept out during the heating period.

\section{Purge time}

During the $\mathrm{NaBH}_{4}$ addition ( $5 \mathrm{~min}$ ), the arsines formed were swept out of the solution by helium flushing before being trapped in the refrigerated column. To ensure complete trapping, the column was then left in liquid nitrogen. We have

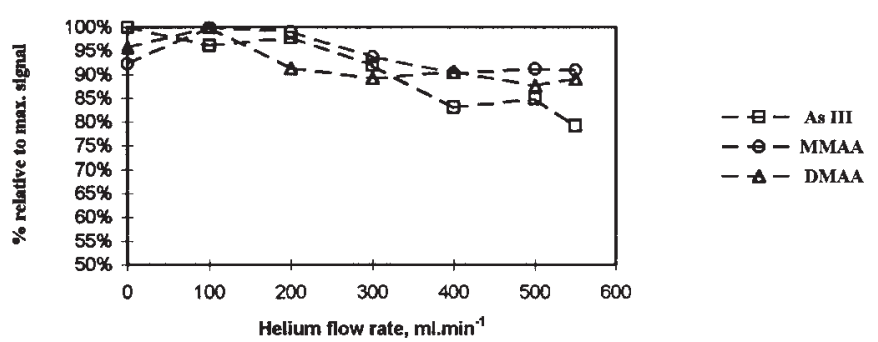

Fig. 6. Effect of initial helium flow rate on arsine, monomethylarsine and dimethylarsine signal areas. (Mass of As $10 \mathrm{ng} ; \mathrm{NaBH}_{4}$ amount: $600 \mathrm{mg}$; oxalic acid concentration: $1 \%$ ).

tested this purge time in the range $30 \mathrm{~s}$ to $2 \mathrm{~min}$. No changes of signals were observed leading to the conclusion that a quantitative trapping was obtained within a $30 \mathrm{~s}$ purge time.

\section{Column temperature gradient}

After trapping, the column was removed from liquid $\mathrm{N}_{2}$ at room temperature during $3 \mathrm{~min}$. This time was sufficient to detect arsine, monomethylarsine, dimethylarsine and trimethylarsine at retention times of $0.5,1.7,2.3$ and 2.7 min, respectively. However, at room temperature, water was only slowly volatilized and caused a baseline drift in consecutive experiments. The column was then heated for $3 \mathrm{~min}$ with an applied temperature gradient of $40{ }^{\circ} \mathrm{C} \times \mathrm{min}^{-1}$. It was found sufficient to remove quantitatively water without damaging the packing.

\section{Optimization of detection parameters}

Effects of parameters concerning atomisation conditions, such as cell geometry, gas flow rates and quartz cell heating, have been already optimized in our laboratory for organotin speciation [55]. The same cell design, well described in this last mentioned paper, was used in this study.

\section{Additive gas flow rates}

It has been previously shown that the $\mathrm{H}_{2} / \mathrm{O}_{2}$ flame produced at the end of the $\mathrm{O}_{2}$ inlet tube by the addition of theses gases in the heated quartz cell improves considerably the sensitivity of the HG-QFAAS method due to the production of $\mathrm{H}^{\bullet}$ radicals which increase hydrides atomization [56]. The $\mathrm{H}_{2} / \mathrm{O}_{2}$ gas flow rates values depend of each cell design and of electrical heating device. The experimental observations are presented on figure 7 for inorganic arsine. The same effects were observed for methylarsines.

Whatever the oxygen flow rate studied from 40 to $100 \mathrm{~mL} \cdot \mathrm{min}^{-1}$, a $200 \mathrm{~mL} \times \mathrm{min}^{-1} \mathrm{H}_{2}$ flow rate led to very low signal intensities. The quantity of $\mathrm{H}^{\bullet}$ radicals is then no more sufficient to react with hydrides and to liberate free arsenic atoms prior their detection $[55,56]$. The $\mathrm{H}_{2}$ flow rate value had to be at least of $300 \mathrm{~mL} \times \mathrm{min}^{-1}$ to improve sensitivity and above this value signals areas were stable. 


\section{Original articles}

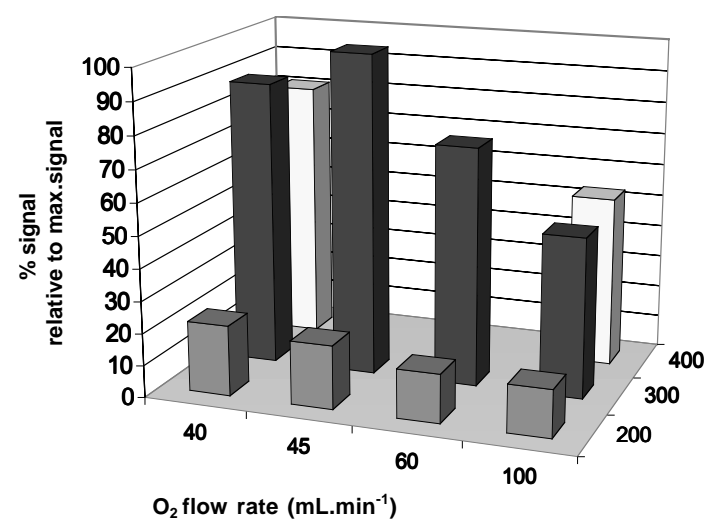

$\mathrm{H}_{2}$ flow rate $\left(\mathrm{mL} . \mathrm{min}^{-1}\right)$

$\mathrm{O}_{2}$ flow rate $\left(\mathrm{mL} \cdot \mathrm{min}^{-1}\right)$

Fig. 7. Effect of $\mathrm{O}_{2}$ and $\mathrm{H}_{2}$ flow rates on the detection of arsine $\mathrm{AsH}_{3}$ in the quartz cell.

For $300 / 400 \mathrm{~mL} \times \min ^{-1} \mathrm{H}_{2}$ and above $45 \mathrm{~mL} \times \mathrm{min}^{-1}$ $\mathrm{O}_{2}$ flow rates, a decrease of signal areas was observed. This decrease is due to the dilution of $\mathrm{H}^{*}$ radicals cloud in the reactive zone by a too high $\mathrm{O}_{2}$ supply [56]. Therefore, optimal flows were chosen at $45 \mathrm{~mL} \times \mathrm{min}^{-1}$ for $\mathrm{O}_{2}$ and $300 \mathrm{~mL} \times \min ^{-1}$ for $\mathrm{H}_{2}$.

\section{Atomiser cell temperature}

The quartz furnace temperature reported in the literature for arsenic compounds was in the range $800-1000{ }^{\circ} \mathrm{C}$ as for Se or Sn hydrides [56]. We effectively did not observed significant signal differences in this temperature range. Finally, the temperature was fixed at $800{ }^{\circ} \mathrm{C}$ to reduce the quartz tube surface decomposition which accelerate recombination of radicals leading to a lower atomization efficiency and then to a loss of sensitivity $[55,56]$.

\section{Wavelength}

The most sensitive and most often used wavelength for the atomic absorption determination of As is $193.7 \mathrm{~nm}$. However, a similar sensitivity (signal/noise ratio) was observed at $197.3 \mathrm{~nm}$ and the baseline alteration due to water vapor is much more important at $193.7 \mathrm{~nm}$ than at $197.3 \mathrm{~nm}$ affecting integration reproducibility.

The use of a $\mathrm{D}_{2}$-arc background correction led to a $20 \%$ decrease in sensitivity and the detection limits were not improved.

\section{Analytical performances}

A typical standard chromatogram is presented in figure 8 . Table I summarizes the final optimized conditions retained for the method application.

The analytical performances, presented in table II, were obtained from five different calibration curves of each standard prepared in suprapure water.

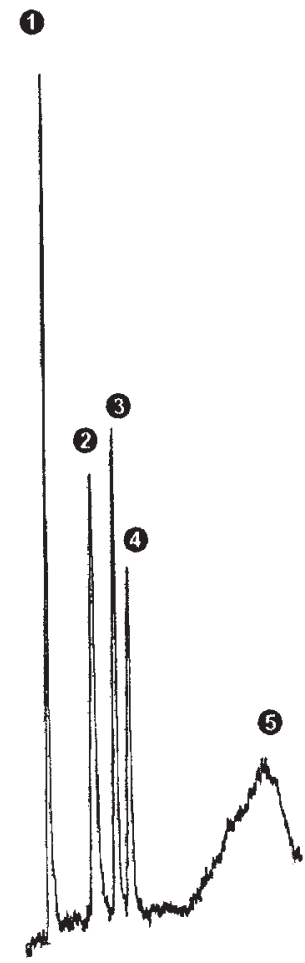

$$
\begin{array}{ll}
\text { (1) } \mathrm{AsH}_{3} & \mathrm{tr}=0.5 \mathrm{~min} \\
\text { (2) }\left(\mathrm{CH}_{3}\right) \mathrm{AsH}_{2} & \mathrm{tr}=1.7 \mathrm{~min} \\
\text { (3 }\left(\mathrm{CH}_{3}\right)_{2} \mathrm{AsH} & \mathrm{tr}=2.3 \mathrm{~min} \\
\text { (4 }\left(\mathrm{CH}_{3}\right)_{3} \mathrm{As} & \mathrm{tr}=2.7 \mathrm{~min} \\
\text { (5 water, } & \mathrm{tr}>4 \mathrm{~min}
\end{array}
$$

Fig. 8. Typical HG/QFAAS standard chromatogram of $10 \mathrm{ng}$ inorganic As, MMAA, DMAA and TMAO.

Our absolute detection limits in the range of 0.1 to $0.5 \mathrm{ng}$ are similar to those reported in the literature for similar batch HG/QFAAS systems. For example Andreae [39] obtained a range of 0.1 to $2 \mathrm{ng}$. Michel et al. [47] and Masscheleyn et al. [46] obtained $0.2 \mathrm{ng}$ and $2 \mathrm{ng}$ for all arsenic species respectively. It is interesting to note that using AFS detector instead of QFAAS, Featherstone et al. [36] would observed much better results if they could used a $50 \mathrm{ml}$ volume of sample. However using $5 \mathrm{ml}$ of sample as it is decribed in their paper, relative detection limits (0.9 to $3.7 \mathrm{ng} . \mathrm{L}^{-1}$ ) are similar than ours.

Nevertheless our analytical performances are such that the method can be easily employed for arsenic speciation in environmental samples knowing that the European recommandation for total As concentration in drinking water sample were recently (Nov. 1998) reduced from 50 to $10 \mu \mathrm{g} . \mathrm{L}^{-1}$.

\section{Arsenic speciation in environmental samples}

Due to the lack of reference material for As speciation, the validity of our analytical method was first tested on a mineral water spiked with AsIII, AsV, MMAA and DMAA.

As seen in table III, theoretical and experimental concentrations were very well correlated, with standard devia- 
Table I. HG/QFAAS operating parameters.

\begin{tabular}{|c|c|}
\hline \multicolumn{2}{|l|}{ Hydride generation } \\
\hline \multicolumn{2}{|l|}{ Acid nature: } \\
\hline \multicolumn{2}{|c|}{ exp.I: As (III + V), MMAA, } \\
\hline DMAA & oxalic acid $1 \%(50 \mathrm{ml})$ \\
\hline exp.II: As III only & phosphate buffer $0.05 \mathrm{~mol} \times \mathrm{L}^{-1}(50 \mathrm{ml})$ \\
\hline \multicolumn{2}{|l|}{$\mathrm{NaBH}_{4}:$} \\
\hline Concentration & $6 \%$ in $\mathrm{NaOH} 0.1 \mathrm{~mol} \times \mathrm{L}^{-1}$ \\
\hline Flow rate (time) & $2 \mathrm{ml} \times \min ^{-1}(5 \mathrm{~min})$ \\
\hline
\end{tabular}

Trapping

Column

Packing

glass U- tube (pyrex $705 \times 4 \mathrm{~mm} \varnothing)$

(80/100 mesh)

Trapping time $\quad 5.5 \mathrm{~min}$

Room temperature time $3 \mathrm{~min}$

Heating time $\quad 3 \mathrm{~min}\left(40^{\circ} \mathrm{C} \times \mathrm{min}^{-1}\right)$

Initial helium flow rate $100 \mathrm{ml} \times \min ^{-1}(\exp . \mathrm{I})$

$600 \mathrm{ml} \times \min ^{-1}$ (exp.II)

Detection

$\begin{array}{ll}\text { Lamp current } & 8 \mathrm{~mA} \\ \text { Wavelength } & 197.3 \mathrm{~nm} \\ \text { Quartz cell temperature } & 800{ }^{\circ} \mathrm{C} \\ \mathrm{O}_{2} \text { flow rate } & 45 \mathrm{~mL} \mathrm{~min} \\ \mathrm{H}_{2} \text { flow rate } & 300 \mathrm{~mL} \mathrm{~min}\end{array}$

tions below $5 \%$, except for the results concerning AsV which were obtained by difference between two experimental values.

\section{Water samples}

Two river waters have been sampled in Corsica (France). The first samples comes from a small river nearby a deserted realgar mine, thus explaining its high concentration in inor- ganic arsenic. The second sample is from a larger river receiving the tribute of the first mentionned which explains the observed dilution effects on AsV concentration.

The results of arsenic speciation observed in these water samples (Tab. IV) are not unexpected since it has been already documented that $\mathrm{AsV}$ is the predominant or the only form detected in such aerated waters because of their oxidizing conditions [3].

Water flowing from an industrial sludge composting unit has also been analysed (Tab. IV). In this sample DMAA is the most important constituant. The suspected previous pollution of this industrial sludge by sodium cacodylate many years ago could explain this high DMAA concentration. Non quantifiable traces of TMAO were also detected that could originate from the microbiological transformation of inorganic arsenic in the compost. Cross verifications of this analysis by HPLC/ICP-MS or HPLC/HG/QFAAS methods were unsuccessful. Indeed, the concentration in this compost juice are such that with our device we have to dilute it with a 200 dilution factor. Detection limits of HPLC hyphenated systems are such that they have introduced the sample whithout dilution or pretreatment leading probably to problems on the column by this complex matrix.

\section{Sewage sludge}

A microwave digestion procedure optimized in our laboratory to dissolve dry sludges prior to total selenium analysis [57] was tested on a reference sewage sludge certified for its total arsenic content (CRM 007-040). The analysis by HG/QFAAS of this sludge after digestion allowed the detection of inorganic arsenic but also of MMAA and DMAA. This microwave digestion procedure was tested on MMAA and DMAA standard solutions to verify that no loss of these species and no change in their chemical forms occurred during this treatment: 95 - $100 \%$ of MMAA and DMAA standards were recovered in their initial form. Moreover, spikes with standard solutions carried out on the sludge before the microwave solubilisation were quantitatively recovered (Tab. IV). The certified value for total arsenic was recovered with inorganic arsenic as the dominant form $(80 \%)$

Table II. Performances of the HG/QFAAS method.

\begin{tabular}{|c|c|c|c|c|c|c|}
\hline & $\begin{array}{c}\text { AsIII } \\
p H=6.8\end{array}$ & $\begin{array}{c}\text { AsIII } \\
p H=1.5\end{array}$ & $\begin{array}{c}A s V \\
p H=1.5\end{array}$ & $M M A A$ & $D M A A$ & TMAO \\
\hline Reproducibility $(\%)^{1}$ & 4 & 3 & 3 & 4 & 5 & 6 \\
\hline Absolute Detection Limit (ng As) ${ }^{2}$ & 0.2 & 0.5 & 0.5 & 0.1 & 0.2 & 0.3 \\
\hline Relative Detection Limit (ng As. $\left.\mathrm{L}^{-1}\right)^{3}$ & 4 & 11 & 11 & 3 & 3 & 6 \\
\hline Linearity Range (ng As) & $0.2-25$ & $0.5-20$ & $0.5-20$ & $0.1-20$ & $0.2-20$ & $0.3-20$ \\
\hline Correlation $(\%)^{4}$ & 99.8 & 99.7 & 99.9 & 99.9 & 99.9 & 99.6 \\
\hline
\end{tabular}




\section{Original articles}

Table III. Theoretical and experimental arsenic species concentrations in a spiked mineral water.

\begin{tabular}{|c|c|c|c|c|c|}
\hline & Inorganic As & AsIII & $A s V$ & $M M A A$ & $D M A A$ \\
\hline Theoretical values & 250 & 150 & 100 & 200 & 300 \\
\hline${ }^{1}$ Experimental values & $263 \pm 13$ & $144 \pm 7$ & $119 \pm 20$ & $208 \pm 10$ & $312 \pm 16$ \\
\hline
\end{tabular}

${ }^{1}$ results obtained by standard additions and expressed as: mean of 3 determinations \pm standard deviation.

Table IV. Speciation of arsenic in environmental samples.

\begin{tabular}{|c|c|c|c|c|c|c|c|}
\hline & Inorganic As & AsIII & $A s V$ & $M M A A$ & $D M A A$ & TMAO & As total (summation) \\
\hline River 1 (ng. $\mathrm{mL}^{-1}$ ) & $2300 \pm 200$ & n.d & $2300 \pm 200$ & n.d & n.d & n.d & $2300 \pm 200$ \\
\hline River 2 (ng. $\mathrm{mL}^{-1}$ ) before confluence & $0.96 \pm 0.04$ & n.d & $0.96 \pm 0.04$ & n.d & n.d & n.d & $0.96 \pm 0.04$ \\
\hline after confluence & $95 \pm 5$ & n.d & $95 \pm 5$ & n.d & n.d & n.d & $95 \pm 5$ \\
\hline Compost juice (ng.mL $L^{-1}$ ) & $28 \pm 1$ & $3.2 \pm 0.2$ & $25 \pm 1$ & n.d & $86 \pm 4$ & traces & $114 \pm 5$ \\
\hline Sewage sludge $\left(\mu \mathrm{g} \cdot \mathrm{g}^{-1}\right)$ & $4.9 \pm 0.1$ & I & l & $0.63 \pm 0.06$ & $0.18 \pm 0.05$ & n.d & $5.7 \pm 0.2$ \\
\hline CRM 007-040 & & & & & & & $(5.74)^{1}$ \\
\hline Addition of $0.4 \mu \mathrm{g} \cdot \mathrm{g}^{-1}$ MMAA & / & / & l & $0.975 \pm 0.05$ & l & n.d & \\
\hline Addition of $0.2 \mu \mathrm{g} \cdot \mathrm{g}^{-1}$ DMAA & l & l & l & l & $0.41 \pm 0.02$ & n.d & \\
\hline recovery $(\%)$ & l & l & l & $95 \%$ & $108 \%$ & n.d & \\
\hline
\end{tabular}

Results obtained by standard additions and expressed as: mean of 3 determinations \pm standard deviation. n.d: no detected; /: not analysed; ${ }^{1}$ CRM certified value: $4.89<5.74<6.59 \mu \mathrm{g} \mathrm{As.} \mathrm{g}^{-1}$.

while MMAA and DMAA were quantified as only $10 \%$ of total value.

\section{Conclusion}

After optimization of the analytical parameters, the application of the HG/QFAAS method to environmental samples analysis has proven its efficiency for the speciation of arsenic. The method presents several important advantages. Its very high sensitivity often allows a significant dilution of samples so that matrix interferences are considerably reduced. In the analysis of clean waters, sample volume can be increased, thus lowering detection limits, a procedure which is not possible in analytical methods using a sample injection loop with fixed volume. The separation of volatile components from the matrix and their preconcentration into a cryogenic trap before detection was also of great help for complex samples. However, it can be objected that it is limited to the measurement of species which form volatile arsenic derivatives and can not be directly applied to analyse arsenobetaïne or arsenocholine that are the major compounds detected in sea food (marine fish, molluscs, crustaceans) or dimethylarsenosugars present in marine algae $[11,12]$. Sample pretreatment such as photolysis [50] are thus necessary in order to determine these compounds by HG/QFAAS.
Nevertheless, the simplicity of the method and the low costs of equipment and analysis make the HG/QFAAS method of interest for the determination of arsenic species encountered in environmental samples such as waters, soils, sediments and sludge.

\section{References}

1. Yan-Chu, H. Arsenic in the environment, Part 1: cycling and characterization, Wiley \& Sons, New-York, 1994, chap.2, p.17.

2. Bhumbla, D.K.; Keefer, R.F. Arsenic in the environment, Part 1: cycling and characterization, Wiley \& Sons, New-York, 1994, chap. 3, 51.

3. Mok, W.M.; Wai, C.M. Arsenic in the environment, Part 1: cycling and characterization, Wiley \& Sons, New-York, 1994, chap. $5,99$.

4. Azcue, J.M.; Nriagu, J.O. Arsenic in the environment, Part 1: cycling and characterization, Wiley \& Sons, New-York, 1994, chap. 1,1 .

5. Iffland, R. Handbook of metals in clinical and analytical chemistry, Marcel Dekker, Inc. New-York, Basel, Hong-Kong, 1994, chap. 18, 237.

6. Cullen, W.R.; Reimer, K.J. Chem. Rev. 1989, 89, 713.

7. Tamaki, S.; Frankenberger, W.T. Rev. Environ. Contam. Toxicol. 1992, 124, 79.

8. Anderson, L.C.D.; Bruland, K.W. Environ. Sci. Technol. 1991, 25, 420. 
9. Maeda, S. Arsenic in the environment, Part 1: cycling and characterization, Wiley \& Sons, New-York, 1994, chap. 8, 155.

10. Vahter, M. Appl. Organomet. Chem. 1994, 8, 175.

11. Neff, J.M.; Environ. Toxicol. Chem. 1997, 16, 917.

12. Francesconi, K.A.; Edmonds, J.S. Arsenic in the environment, Part 1: cycling and characterization, Wiley \& Sons, New-York, 1994, chap. 10, 211.

13. Hanaoka, K.; Tagawa, S.; Kaise, T. Appl. Organomet. Chem. 1992, 6, 139.

14. Le, S.X.C.; Cullen, W.R.; Reimer, K.J. Environ. Sci. Technol. 1994, 28, 1598.

15. Cullen, W.R.; Reimer, K.J.; Appl. Organomet.Chem. 1994, 8, 303.

16. Cullen, W.R.; Li, H.; Pergantis, S.A.; Eigendorf, G. K.; Mosi, A.A. Appl. Organomet.Chem. 1995, 9, 508.

17. Yamauchi, H.; Fowler, B.A. Arsenic in the environment, Part II: Human Health and ecosystems effects, Wiley \& Sons, NewYork, 1994, chap. 3, 35.

18. Irgolic, K.J. Hazardous metals in the environment, Elsevier, Amsterdam, 1992, chap. 12, 288.

19. Morita, M.; Edmonds, J.S. Pure \& Appl. Chem. 1992, 64, 575.

20. Crompton, T.R. The chemistry of organic arsenic, antimony and bismuth compounds, Wiley \& Sons, New-York, 1994, chap. 5, 169.

21. Amran, B.; Lagarde, F.; Leroy, M.J.F.; Lamotte, A.; Demesmay, C.; Olle, M.; Albert, M.; Rauret, G.; LopezSanchez, J.F. Quality Assurance for Environmental Analysis, Elsevier, Amsterdam, 1995, chap.12, 285.

22. Burguera, M.; Burguera, J.L. Talanta 1997, 44, 1581.

23. Guerin, T.; Astruc, A.; Astruc, M. Talanta in press.

24. Gailer, J.; Irgolic, K.J. Appl. Organomet. Chem. 1994, 8, 129.

25. Hansen, S.H.; Larsen, E.H.; Pritzi, G.; Cornett, C. J. Anal. Atom. Spectrom. 1992, 7, 629.

26. Woller, A.; Mester, Z.; Fodor, P. J. Anal. Atom. Spectrom. 1995, 10, 609.

27. Hill, S.J.; Bloxham, M.J.; Worsfoldp, J. J. Anal. Atom.Spectrom. 1993, 8, 499.

28. Rubio, R.; Padro, A.; Alberti, J.; Rauret, G. Mikrochim. Acta 1992, 109, 39.

29. Guerin, T.; Astruc, M.; Batel, A.; Borsier, M. Talanta 1997, 44, 2201.

30. Le, X.C.; Cullen, W.R.; Reimer, K.J. Talanta 1994, 41, 495.

31. Thomas, P.; Sniatecki, K. Fresenius J. Anal. Chem. 1995b, $351,410$.
32. Lamble, K. J.; Hill, S. J. Anal. Chim. Acta 1996, 334, 261.

33. Rubio, R.; Padro, A.; Rauret, G. Fresenius J. Anal. Chem. 1995, 351, 331.

34. Gomez, M.; Camara, C.; Palacios, M. A.; Lopez-Gonzalvez, A. Fresenius J. Anal. Chem. 1997, 357, 844.

35. Hwang, C.J.; Jiang, S. J. Anal. Chim. Acta 1994, 289, 205.

36. Featherstone, A. M.; Butler, E. C. V.; O'Grady, B. V.; Michel, P. J. Anal. Atom.Spectrom. 1998, 13, 1355.

37. Le, X.C.; Ma, M.S. Anal. Chem. 1998, 70, 1926.

38. Gomez-Ariza, J.L.; Sanchez-Rodas, D.; Beltran, R.; Corns, W.; Stockwel, P. Appl. Organomet. Chem. 1998, 12, 439.

39. Andreae, M.O.; Anal.Chem. 1977, 49, 820.

40. Braman, R.S.; Jonhson, D.L., Foreback, C.C.; Ammons, J.M.; Bricker, J.L Anal.Chem. 1977, 49, 621.

41. Feldman, C. Anal.Chem. 1979, 51, 664.

42. Arbab-Zavar, M.H.; Howard, A.G. Analyst 1980, 105, 744.

43. Howard, A.G.; Arbab-Zavar, M.H. Analyst 1981, 106, 215.

44. Glaubig, R.A.; Goldberg, S. Soil. Sci. Soc. Am. J. 1988, 52, 536.

45. Howard, A.G.; Comber, S.D.W. Mikrochim. Acta 1992, 109, 27.

46. Masscheleyn, P.H.; Delaune, R.D.; Patrick, W.H. J. Environ. Qual. 1991, 20, 96.

47. Michel, P.; Averty, B.; Colandini, V. Mikrochim. Acta 1992, 109, 35.

48. Anderson, R.K.; Thompson, M.; Culbard, E. Analyst 1986, 111,1143 .

49. Hasegawa, H.; Sohrin, Y.; Matsui, M.; Hojo, M.; Kawashima, M. Anal. Chem. 1994, 66, 3247.

50. Howard, A.G.; Salou, C. Anal. Chim. Acta 1996, 333, 89.

51. Le, S.X.C.; Cullen, W.R.; Reimer, K.J. Appl. Organomet.Chem. 1992, 6, 161.

52. Rude, T.R.; Puchelt, H. Fresenius J. Anal. Chem. 1994, 350, 44.

53. Astruc, M.; Pinel, R.; Astruc, A. Mikrochim. Acta 1992, 109, 73.

54. Braman, R.S.; Foreback, C.C. Science 1973, 182, 1247.

55. Sarradin, P.M.; Leguille, F.; Astruc, A.; Pinel, R.; Astruc, M., Analyst 1995, 120, 79.

56. Dedina, J. Prog. Analyst. Spectrosc. 1988, 11, 251.

57. Heninger, I.; Potin-Gautier, M.; Astruc, M.; Galvez, L.; Vignier, V. J. Anal. Atom. Spectrom. 1998, 13, 1. 